\title{
Is There a Link between Exercise and Male Factor Infertility? ${ }^{\dagger}$
}

\author{
Stefan S. du Plessis ${ }^{1}$, Anthony Kashou ${ }^{2}$, Diana Vaamonde ${ }^{3}$ and Ashok Agarwal ${ }^{*}, 2$ \\ ${ }^{I}$ Division of Medical Physiology, Stellenbosch University, Tygerberg, South Africa \\ ${ }^{2}$ Center for Reproductive Medicine, Cleveland Clinic, Cleveland, Ohio, USA \\ ${ }^{3}$ Morphological Sciences Department, School of Medicine, University of Cordoba, Spain
}

\begin{abstract}
The beneficial effects of physical exercise on general health are well known; however, as exercise imposes great physical stress that challenges homeostasis, it can be detrimental to certain organs/systems of the body when it is exhaustively performed. Decreased seminal parameters and sex hormone levels have been reported in male athletes and, therefore, a possible impairment of male fertility has been linked to exercise in a volume, intensity, and modality dependent-manner. Also, inherent characteristics of sportsmen (e.g. training level, adaptive capacity) may modify the response. This article aims to review the relevant literature regarding exercise and male factor infertility, while at the same time explores the possible underlying mechanisms that might be involved in this observable fact.
\end{abstract}

Keywords: Exercise, male fertility, sperm, hormones, oxidative stress.

\section{INTRODUCTION}

Regular exercise and physical activity promote overall health benefits that are hard to ignore. The benefits of exercise have been known since antiquity as Marcus Cicero, around $65 \mathrm{BC}$, stated: "It is exercise alone that supports the spirits, and keeps the mind in vigor" [1]. Interestingly enough, the first scientifically based link between physical health and exercise, or lack of it, was only reported as recently as 1953 by Jerry Morris [2,3]. Since then, exercise has been regarded as a universal remedy for psychological and physical wellbeing, from preventing chronic health conditions to promoting weight loss and better sleep as underlined by numerous scientific studies [4-9]. Furthermore, Vaamonde et al. have observed that physically active subjects have better semen parameters and hormone levels than sedentary subjects $[10,11]$. It is promoted that the exercise is beneficial regardless of age, sex or physical ability. This statement is widely accepted and no more studies are needed to support this belief. However, the question arises as to what is the right amount to promote the beneficial effects and not have undesired side effects.

The demand and practice of physical and sport activities have greatly increased during the past few decades among both men and women due to the proven health benefits. Simultaneously, there has been a rapid increase in both participating in competitive sports as well as pursuing it as a professional career. Despite this global increased interest in exercising, an inadequate knowledge and ignorance regarding exercise routines can possibly lead to harmful side effects [12]. Some of the most common and noticeable illeffects of exercise are due to physical injuries

*Address correspondence to this author at the Center for Reproductive Medicine, Cleveland Clinic, Cleveland, Ohio 44195, USA; Tel: 2164448182; Fax: 2164456049; E-mail: agarwaa@ccf.org

${ }^{\dagger}$ This research was conducted at the Cleveland Clinic's Center for Reproductive Medicine, Cleveland, Ohio. (musculoskeletal injuries such as strains, sprains or fractures). However, some of the more dangerous effects of excessive exercise are not so evident and exercise can be injurious to some bodily organs and systems, provoking multisystemic damage [13-18]. This phenomenon is possible since exercise, per se, is a physical stress situation that challenges homeostasis [19]. As the number of active participants in physical exercise and sport increases over time, it is crucial to understand the impact that such exercising mode may have.

There is growing evidence and concern that exercise, especially when excessively practiced, may lead to adverse effects on the reproductive system and fertility [20]. Several authors have reported that sports activities can lead to luteal phase defects, exercise-associated amenorrhea, and infertility in females [20-28]. This phenomenon is commonly referred to as "exercise-related female reproductive dysfunction" [19]. Conversely, little information regarding this topic is available in males as very few authoritative studies have been carried out on this subject.

Couple infertility is increasing world-wide with male factor infertility contributing approximately the same as female infertility towards this devastating pathology [29, 30]. Regardless of many advances in the field of andrology, the biggest concerns are still the idiopathic components of male factor infertility [31]. As some of the novel research shows, exercise could just be one of the underlying causative factors. Keeping this in mind, our review aims to highlight the pathological aspects of exercise in male fertility and the possible mechanisms involved by reviewing the pertinent available literature.

\section{MATERIALS AND METHODS}

In order to evaluate the effect of physical exercise and sports on male infertility a systematic review was conducted. Literature deemed relevant to male reproductive dysfunction 
and exercise was retrieved from PubMed. Appropriate search terms such as exercise, sports, physical activity, male infertility, reproduction, semen and sperm were used. All abstracts were carefully read and assessed; articles referring to physical trauma and/or the use of anabolic steroids, as well as those manuscripts that were not available in English language, were omitted.

\section{PATHOLOGICAL AND CLINICAL PROOF}

The male reproductive system consists of the hypothalamic-pituitary-gonadal (HPG) axis, with the testes being responsible for both endocrine (i.e. production of steroidal hormones - predominantly the androgen testosterone) and exocrine (i.e. production of spermatozoa) functions. The HPG axis operates under a negative feedback system, with the major gonadal regulatory hormone being testosterone [32]. The hypothalamus secretes gonadotropin releasing hormone (GnRH) in pulses; this hormone, in turn, stimulates the release of luteinizing hormone (LH) and follicle-stimulating hormone (FSH) from the anterior-pituitary gland. LH stimulates the Leydig cells in the testis to secrete testosterone, while FSH assists spermatogenesis. Another hormone produced by the pituitary, prolactin, is also involved in the regulation of sex steroid production [33]. It is easily understood that any factor altering this axis would therefore automatically affect male fertility. Yet published findings regarding the effects of exercise on male fertility remain ostensibly ambiguous and contradictory. A number of studies did not show any changes in semen parameters between athletes [34-36], however, noteworthy effects have been reported by some researchers [12,13,37-40]. Some of these findings will subsequently be discussed.

Hall and co-workers reported that intensified training due to increased running distance (6 week step-wise increase to $186 \%$ of normal training) and detraining ( 2 weeks at $50 \%$ of normal training) did not influence testicular function with respect to sperm count, sperm morphology, and sperm motility. It was furthermore established that neither cortisol nor the reproductive hormones were altered. The authors remark that a particular level or degree of training must be surpassed before any clinical alterations become evident [41]. Other authors also supported this notion as they concluded from their findings that a volume threshold for the effect of training on sperm parameters and hormones does truly exist $[13,42,43]$. Such volume threshold has been observed both in running and in cycling. The study by Vaamonde et al. showed that, in high-level athletes that have been training for years, it would be difficult to estimate the threshold to start observing abnormal semen parameters, yet it seems that a high cycling volume is detrimental to sperm morphology [13]. Moreover, the same authors report that a volume of $300 \mathrm{~km} /$ week in cycling correlates with serious fertility impairment from the sperm morphology point of view (Fig. 1)

In a study by Arce et al., endurance-trained and resistance-trained athletes presented with significantly lower levels of total and free testosterone, compared with sedentary controls. No significant differences in serum levels of all other circulating hormones (LH, FSH, prolactin, and estradiol), and urinary LH measurements were found among the three groups. Sperm density, motility, morphology and in vitro sperm penetration of standard cervical mucus were significantly altered only in the endurance-trained runners [37]. The authors concluded that both endurance and resistance training modify the male reproductive hormone profile in a similar manner; however, only endurance training, in the form of running, is associated with subclinical modifications in semen characteristics [37].

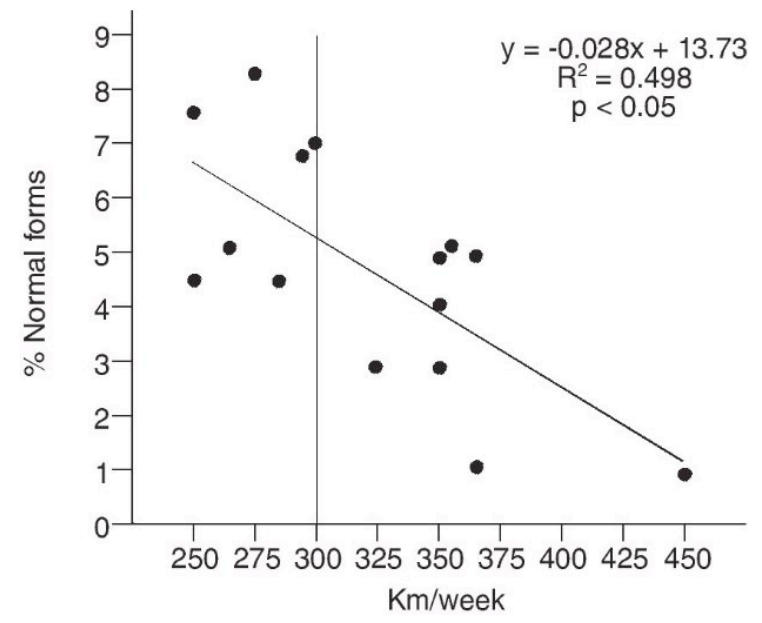

Fig. (1). Correlation between percentage of sperm with normal morphology and cycling weekly volume (expressed as $\mathrm{Km} / \mathrm{week}$ ). Taken from Vaamonde et al. 2009 (Rev Andal Med Deporte); 2(2): 43-6.

Similarly, De Souza and co-workers reported that the levels of total testosterone and free testosterone were significantly lower in high-mileage runners compared to moderate-mileage runners and sedentary controls. They found no differences in either serum LH, FSH, and prolactin or in urinary LH levels among the three groups. Sperm concentration, total number of motile sperm and sperm penetration of bovine cervical mucus were also significantly lower in high-mileage runners compared to sedentary controls. Furthermore, an increased population of immature sperm and round cells were observed in high-mileage runners as opposed to the other two groups. These researchers showed that training volume (expressed as $\mathrm{km} / \mathrm{week}$ ), was significantly correlated to sperm motility, density and number of round cells, while total testosterone significantly correlated to number of round cells. The authors even suggested that well defined differences in reproductive function (gonadal steroids and altered semen quality) exist between high-mileage runners (high volume of endurance running) and those runners participating in more moderate training volumes [42].

Another study compared sperm parameters of men partaking in three different training modalities (physically active men, water polo players, and triathletes). Sperm concentration/number, velocity, and morphology were significantly different among the participants of the three different training modalities. The parameter showing the greatest difference was morphology, even reaching clinical relevance for the triathlete group $(<5 \%$ normal forms) $[12,44]$.

In one of the most comprehensive and controlled studies to date on the effect of exercise on the reproductive hormones and semen quality, Safarinejad and co-workers 
randomly distributed 286 subjects to moderate-intensity exercise $\left(60 \%\right.$ of $\left.\mathrm{VO}_{2 \max }\right)$ and high-intensity exercise $(80 \%$ of $\left.\mathrm{VO}_{2 \max }\right)$ groups [38]. Both groups exercised for 60 weeks (treadmill running for 120 minutes, 5 sessions/week) followed by a 36-week low-intensity recovery period. From 12 weeks onward, serum testosterone and free testosterone began to decrease, while serum sex hormone binding globulin began to increase with both moderate- and highintensity exercises. Moreover, serum LH and FSH concentrations decreased below baseline levels in both groups. When a GnRH stimulation test was conducted, LH and FSH responses were also blunted. Midway through the runningphase, the subjects in the high-intensity exercise group showed a significant decline in semen parameters compared to those athletes exercising at moderate intensity. Interestingly enough, all of the above mentioned parameters improved to their pre-exercise levels during the recovery period [38]. We have to bear in mind though that the reversible deleterious effects may not be reversible if athletes have been training for longer periods of time (years) or had started training around puberty.

Another study highlighted the fact that long distance competitive cyclists had a significantly lower proportion of spermatozoa with normal morphology and a significantly higher proportion of morphologically abnormal tapered forms compared to controls (no significant difference in semen volume and sperm motility, viability and concentration was observed) [40]. Conversely, Vaamonde et al. showed that seminological values and hormonal profiles differed significantly even in recreational athletes who exercise to the point of exhaustion [45]. These adverse effects of exercise become an aggravating factor in men whose sperm parameters are already compromised due to other pathologies such as varicocele [46].

Erectile dysfunction (ED) or impotence has also been attributed to continuous strenuous exercise [47]. Tiredness and fatigue may reduce sexual desire and libido to the extent that it is impossible to get or sustain an erection. This phenomenon is highly associated with bicycling, as multiple studies repeatedly demonstrated the increased risk of ED in cyclists [48-52].

It becomes more apparent that it is not a simple fact of exercise leading to infertility, but rather that inherent parameters of exercise such as type, volume, and intensity must also be taken into consideration and carefully analyzed.

\section{PLAUSIBLE MECHANISMS}

From the preceding section it is evident that adequate evidence exists to warrant discussing potential mechanisms via which exercise, in various forms, can adversely affect the male reproductive system. Several plausible mechanisms as to how exercise affects male reproductive potential, either directly or indirectly, will subsequently be explored. It is difficult to determine and pinpoint the particular mechanisms that can play a role as there are numerous confounding factors such as inappropriate food intake, fatigue and decreased body weight [53-55]. While abnormal hormonal milieu could be attributable to a decrease in body fat and altered steroidogenesis, many studies show differences between athletes with different training load without statistical significances in weight or fat percentage. It is well known that exercising can lead to testicular injuries, while some sportsmen, both leisure and professional, use anabolic steroids to enhance their performance. These factors can have direct negative impact on fertility, but will not be discussed here as they fall outside the scope of this manuscript. Consequently to this, only the effects of exercise on oxidative stress, hormonal imbalance, erectile dysfunction, testicular temperature, and testicular trauma will be reviewed (Fig. 2).

\section{Exercise and the Oxidative Stress System}

Oxidative stress (OS) has repeatedly been implicated as a leading cause of male factor infertility [56]. It is well known that increased concentrations in reactive oxygen species (ROS) and reactive nitrogen species (RNS) have a negative effect on sperm parameters. This event takes place because sperm are especially susceptible to the deleterious damage as a result of OS. The sperm plasma membrane is very sensitive to the effect of ROS since it contains abundant unsaturated fatty acids. These unsaturated fatty acids create fluidity which is necessary for sperm motility and membrane fusion events such as the acrosome reaction and sperm-egg interaction. However, the unsaturated nature of these molecules predisposes them to ROS attack and ongoing lipid peroxidation. Though antioxidant defence systems are active in semen, their activity is constrained since the amount of cytoplasm of the sperm cell is limited [57].

Ever since the first report in 1978, which illustrated evidence of an increase in lipid peroxidation following acute aerobic exercise, the field of OS and its correlation to exercise has expanded substantially [58]. Numerous studies

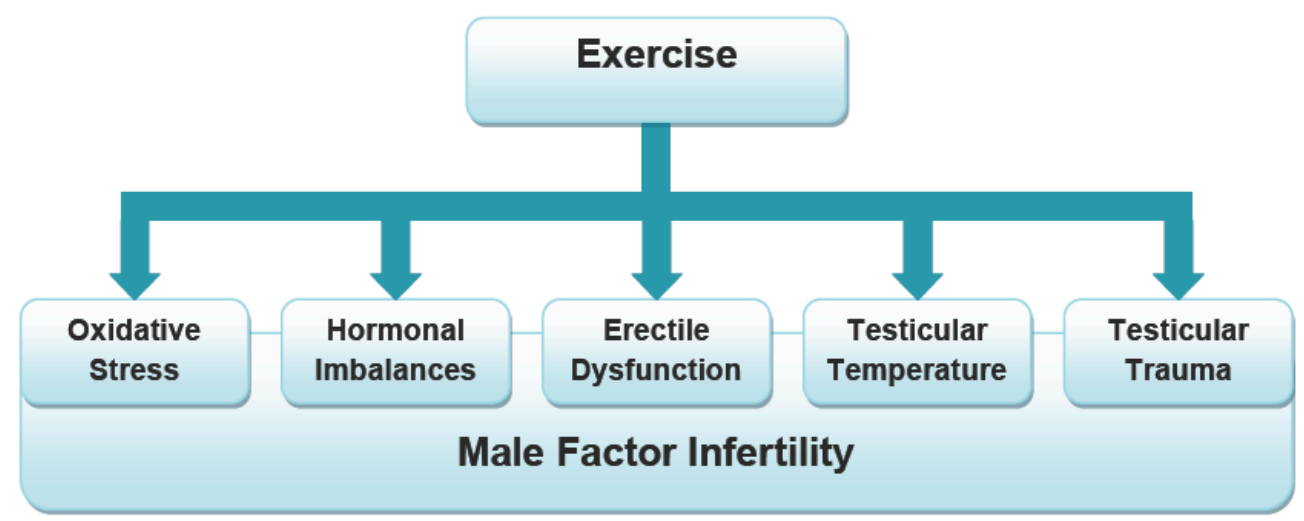

Fig. (2). Possible mechanisms through which exercise can exert an effect on male factor infertility. 
provide proof for the existence of OS biomarkers due to an increase in ROS production during both aerobic and anaerobic exercise [59]. Strenuous exercise represents a physical stress that challenges homeostasis, and, therefore, it may lead to an increased production of ROS or suppression of the antioxidant levels $[20,60]$. It has been confirmed that extreme endurance, such as ironman triathlons and longdistance running events, increase OS indeed [60-62]. While physiological levels of ROS are necessary for normal sperm functionality (maturation, capacitation, hyperactivation, acrosome reaction, and sperm-oocyte fusion), pathological levels may cause lipid peroxidation, DNA damage, and ultimately lead to sperm death [63]. High intensity exercise induces OS and although there is no evidence that this affects sporting performance in the short term, it may have longer term health consequences. The mechanisms of exercise-induced OS are not well understood. While mitochondria are sometimes considered to be the main source of free radicals, in vitro studies suggest they may play a smaller role than was first thought. There is a growing evidence of the importance of haem proteins in inducing OS. The release of metmyoglobin from damaged muscle is known to cause renal failure in exercise in a condition called rhabdomyolysis. Furthermore, levels of methaemoglobin increase during high intensity exercise, while levels of antioxidants, such as reduced glutathione, decrease [64]. It remains unclear whether exercise-induced oxidative modifications have little significance, induce harmful oxidative damage, or are an integral part of redox regulation [59].

Although the body possesses a complex antioxidant defense system against ROS and RNS, neutralization processes during and following exercise are often insufficient to prevent oxidative damage. Furthermore, it is clear from previous studies that exercise of sufficient volume, intensity, and duration is positively correlated to an increase in ROS and RNS production, and, in turn, OS [59,65-68]. Several studies performed in rats have shown an increase in OS and a decrease in hormone levels and sperm cell lineages [69, 70]. Both aerobic and anaerobic exercise have been shown to potentially induce free radical production [71]. The fact that better-trained athletes reveal higher levels of antioxidant defense and lower resting lipid peroxidation levels suggests a mode of adaptation to their strenuous exercise over time; this mechanism further diminishes the adverse effects of high ROS and RNS levels and prevents the onset of OS. However, as Kyparos et al. report in a study with elite rowers, even highly trained rowers exhibit significant blood OS when submitted to a 2000-m rowing ergometer [72]. Therefore, if the excessive ROS and RNS generation is not controlled, it can result in OS [60]. In any case, it is clear that several factors influence the onset of OS, which does not enable to establish a clear detection of its origin [71].

Knez et al. stated that moderate exercise can confer a protective effect against OS [73]. Gomez-Cabrera et al. also reported that exercise in itself can be considered as an antioxidant. The same authors provided a description on how exhaustive exercise can produce OS due to oxidation of glutathione, release of cytosolic enzymes, and other signs of cell damage [74].

Insufficient levels of testosterone (a further result of exercise to be discussed in the next section) can furthermore give rise to growing numbers of immature spermatozoa. These immature cells are also implicated in the production of ROS due to incomplete cytoplasm extrusion. Another possibility is that competition, an event that many athletes are engaged in, causes significant psychological stress [75]. This has been demonstrated in other contexts to negatively affect semen quality [53, 76]. Eskiocak and co-workers showed that mental stress due to final exams significantly increased superoxide dismutase activity, while sperm concentration, motility index and percentage of rapid progressive motility decreased simultaneously [76]. Previous studies also suggested mental stress to have a negative effect on sperm parameters related to the quality of the semen such as density, motility and morphology of the spermatozoa [77, 78].

\section{Exercise and Hormonal Imbalances}

The autonomic nervous system and the hypothalamicpituitary-adrenal (HPA) axis are known to participate in the maintenance of homeostasis [19]. In response to the stress of strenuous exercise, the HPA reacts by elevating plasma cortisol and catecholamine levels [79, 80]. Interestingly enough, some authors report that sustained physical conditioning in elite athletes is associated with a decreased HPA response to exercise and competition $[79,81]$ while some others report increased values during competition [82]. Conversely, highly trained athletes exhibit a chronic yet mild form of hypercorticolism at baseline that may be an adaptation to constant exercise [83]. The proinflammatory cytokine IL-6 is also shown to have greater activation; additionally other proinflammatory factors such as myeloperoxidase, PMN elastase, IL-10, high-sensitive C-reactive protein, have been increased in response to intense competition [84]. Furthermore, exercise stimulates the secretion of growth hormone and prolactin (possibly via cytokines in response to stress), and may influence the type of immunity by stimulating the Thelper 2 response profile $[79,85]$.

Likewise, the stress of exercise inhibits gonadal function through the production of glucocorticoids and cathecholamines, as well as through activation of the corticotropinreleasing hormone (CRH) neurons [19]. The HPG axis can be inhibited at several points by the components of the HPAaxis. CRH suppresses the release of GnRH. In addition, glucocorticoids can predominantly inhibit the secretion of GnRH, thereby restraining the secretion of LH and the subsequent stimulation of the gonads to sex steroid hormone production. It furthermore renders the target tissue of the sex steroids resistant to these hormones. CRH is also a negative regulator of LH action on the Leydig cells. These inhibitory effects subsequently attenuate testosterone production by the Leydig cells $[19,86]$. Apart from the central dysfunction of the HPG axis, alternatively the most likely mechanisms to decrease testosterone biosynthesis are perhaps testicular microtrauma or temperature increase [87].

In the literature there is still controversy as to whether intense physical exercise compromises testicular androgen secretion [31]. However, in the recent study of Safarinejad et $a l$. it was clearly shown that serum testosterone and free testosterone levels decreased in response to exercise [38, 88]. FSH and LH levels also decreased while prolactin levels rose progressively. Such behavior is in agreement with what has 
been previously published by others [45]. Additionally, the group of Safarinejad observed a blunted response of LH and FSH to GnRH stimulation and a blunted response of testosterone to human chorionic gonadotropin stimulation. Exercise as such caused these altered hormonal responses, however they were more pronounced in the high-intensity compared to moderate-intensity exercise group. This study highlights the fact that overtraining may induce hypogonadotropic hypogonadism [38]. Alterations such as decreased LH pulsatility and amplitude can explain why some very highmileage runners experience hypogonadism [89]. It seems clear that at least during the competition, and for several days after, athletes experience an anabolic deficit (decrease in $\mathrm{T} / \mathrm{C}$ ratio) as a result of physical strain, sometimes this anabolic deficit becomes chronic, effect known as overreaching or overtraining [82,90]. These effects have not only been observed in cyclists and runners but also on rowers [91]. Moreover, Naessens et al. have reported the same hormonal behavior in a high-level soccer player. In this case, the athlete had a previous condition (cryptorchidy) which made him more vulnerable to the deleterious effects of training. He experienced a broad spectrum of symptoms, from altered hormone levels and loss of libido to recurrent muscle injury. Regardless, of his own condition, researchers observed lowered $\mathrm{T}$ levels during training, and an unfavorable $\mathrm{T} / \mathrm{C}$ during recovery, after tamoxifen treament, the subject reversed all symptoms [92]. On the other hand, Vaamonde et al. have observed improved semen parameters and hormone levels compared to sedentary subjects $[10,11]$.

It is thus evident that male athletes might suffer deleterious consequences of endurance exercises regarding the hypothalamic regulation of gonadal hormones, which is often the cause of idiopathic hypogonadotropic hypogonadism [47].

As blood hormonal levels (LH, FSH, testosterone, prolactin) correlate well with seminal parameters it is understandable that factors, such as exercise, that change these levels will directly impact male fertility [93].

\section{Exercise and Testicular Temperature}

Human spermatogenesis is a sensitive process and it is well known that testicular temperature must be maintained at approximately $2.5^{\circ} \mathrm{C}$ below core body temperature for normal spermatogenesis. The regulatory role of the scrotum in sustaining this lowered testicular temperature is achieved through the combined function of the cremasteric and dartos muscles (by moving the testicles closer or further away from the body) as well as the pampiniform venous plexus of the spermatic cord (acting as a counter-current heat exchanger) [48].

Elevation of scrotal temperature to normal core body temperature results in complete failure of spermatogenesis in man. Impaired reproductive function due to heat-induced alterations has been reported extensively [94-97]. Evenson et al. demonstrated that increased testicular temperature can have latent effects on sperm chromatin structure and may result in transient release of abnormal sperm with DNA that might be genetically compromised [95]. From these studies, it is clear that constant exposure to any factor that compromises the ability of the scrotum to thermoregulate will result in an adverse effect on one or more aspects of semen quality [98].

As body temperature increases with exercise it has been hypothesized by several authors that the injurious effect of exercise on spermatogenesis can be attributed to increased scrotal temperature rather than hormonal changes $[36,37,48]$. It is reasoned that this phenomenon is more prevalent in cyclists due to wearing of tight-fitting shorts and compression of the scrotum against the saddle and body resulting in decreased thermoregulation $[48,53]$.

Jung and co-workers studied the effect of noncompetitive biking (moderate intensity for an hour) on 25 healthy men. They found an increase in core temperatures during the exercise, but scrotal temperatures (which correlate well with testicular temperatures) in fact did not [99]. This finding correlates with findings in other types of exercise, where scrotal temperature decreases. Increases in scrotal temperature are more often associated with sedentary activities such as sitting [100].

Many of the studies accomplished to identify the effect of exercise-generated heat in the testicles have used cyclists as test subjects. However, the results of these studies have been contradictory and, to date, no one had been able to provide substantial/conclusive evidence that exercise (in this case, bicycle riding) increases or decreases testicular temperatures. It is evident that more studies should be undertaken so as to elucidate whether exercise in fact does increase testicular temperature or not.

\section{Exercise and Erectile Dysfunction}

Many cyclists, over $60 \%$ according to Sommer et al., experience genital numbness and even ED [101]. ED, a persistent inability to achieve and/or maintain an appropriate erection for satisfactory sexual performance, may possibly be caused by an impeded blood flow and pressure on the penile nerves as a result of extended periods of time on the saddle. It has been shown that pudendal nerve (innervates the posterior aspect of the scrotum and the penile base) neuropraxia may lead to numbness and an altered sensation during ejaculation [102]. ED has been associated with reduced NO production and/or its bioavailability to the corporeal smooth muscle [103]. In addition, the increase in contractile factors and generation of superoxide anions have been shown to contribute to ED [104].

Tiredness and fatigue can affect the ability to get or sustain an erection. This may sound strange but being tired can reduce sexual desire and libido to the extent that it is impossible to get or maintain an erection. Exhaustive endurance exercise, especially in overreaching/overtraining states can certainly be fatiguing to the athlete and may, therefore, possibly lead to ED. Cycling is the sports modality that is predominantly associated to ED, with nearly $13-24 \%$ of cyclists reporting ED [48,105]. ED and the other urogenital disorders observed in cyclists show greater incidence in mountain-bikers as compared to road-cyclists [106, 107]. Additionally, an increased prevalence of ED has been observed in long distance cyclists (more than three to four hours per week) [48].

Results from the Massachusetts Male Aging Study (MMAS) show that moderate physical activity, including 
bicycling, may have a protective effect against ED. Despite ED being a serious concern in high-load cyclists, this cannot be generalized to the average cyclists who actually have a decreased likelihood of developing ED [50]. These and other data reinforce the idea that regular physical exercise, moderate in nature, is an important approach in preventing ED associated with pathologies such as diabetes mellitus through re-establishing the balance between NO production and inactivation [103]. Conversely, excessive exercise can trigger the onset of ED.

\section{Exercise and Testicular Microtrauma}

A study by Frauscher and colleagues, performing ultrasound testing, reports that mountain bikers show greater incidence of scrotal and testicular abnormalities as compared to non-bikers [108]. Among the observed abnormalities, some should be highlighted: testicular calcifications, hidrocele, varicocele, and testicular microlithiasis. All these abnormalities could lead to infertility.

\section{CONCLUSION}

Over the past few decades it has been commonly asserted that exercising reduces the risk of developing all kinds of diseases. Despite strong evidence for the health benefits of continued aerobic exercise (cardiovascular protective effects and beneficial influence on the risk of hypertension, diabetes, and stroke), strenuous exercise and overtraining can impair the HPG axis and reproductive capacity of males $[38,48,109]$.

As highlighted in this review, researchers are not completely in agreement on the effect of physical exercise on male reproduction. However, regardless of the inconsistent results, evidence exists that high-load exercise may exert a negative impact on male fertility with a range of effects on the male reproductive system depending on the duration, intensity and type of modalities as well as the athletes' inherent characteristics (e.g. fitness level, adaptive capacity, etc). These effects can manifest through the physical stress response of exercise on the HPG axis, hormones, increased testicular temperature, development of OS and role of fatigue or nerve damage in ED. Independently or integratively, all of these mechanisms can lead to reduced seminal parameters and infertility [45]. Interestingly enough, it was observed that these alterations and impairments of the reproductive system were attenuated upon cessation of high impact exercise and can lead to full recovery [45].

As there are differences in the semen parameters of individuals performing different sports modalities, and, especially, in terms of intensity and volume, these variables should be carefully analyzed and taken into account when designing a training protocol. This aspect ought to receive priority, especially when dealing with elite athletes, in order not to compromise their fertility status [12]. Physicians and urologists should be aware that exercise (and in specific certain intensities and modalities such as bicycling) is a potential and valid cause of a variety of urological and andrological disorders affecting male reproduction [48]. It is therefore proposed that high-load training should be included as a component of male factor infertility [31].
Olive summarises quite well that a cause-effect relationship between intense exercise and altered male reproductive function will only be truly established through well designed studies that are properly controlled [20]. Future investigations should therefore focus on the clinical impact of exercise-related hormonal and semen alterations on fertility capacity [31], and also explore the idea of adding antioxidant supplementation within the context of regular exercise.

Nevertheless, exercise-related reproductive dysfunction remains as a strange paradox as there is a fine line between the correct and incorrect amount of exercise. However, in the context of a physically active population, the beneficial effects of exercise seem to outweigh any possible hazard. In the interim, the best advice to offer to a non-athlete population is to decrease the load of exercise as a precautionary measure in the event of idiopathic male factor infertility.

\section{EXPERT COMMENTARY}

Exercise represents a physical stress that challenges homeostasis on several levels. Apart from the beneficial effects of exercise, there is evidence of exercise-related short- and long-term consequences concerning male reproductive function which can manifest centrally (HPG-axis) or locally (testis OS and temperature). This can lead to decreased reproductive hormone levels, impaired seminal parameters, and ED. Intensity, duration and type of exercise as well as inherent characteristics of individuals (training level, adaptive capacity, etc.) will influence these resultant effects. It is important that physicians and the general public pay attention to exercise as a possible cause of idiopathic male infertility and act precautionary until future research has thoroughly elucidated this relationship.

\section{FIVE-YEAR REVIEW}

There has been a recent increase in the number of studies investigating the possible relationship between exercise and male fertility/infertility. The majority of studies have focused on differences in exercise intensity and volume. However, most studies are not well designed and properly controlled, thereby making it difficult to formulate final conclusions. Despite these shortcomings, it is evident that a large group of male athletes are negatively affected with regards to reproductive potential. Future investigations should be better controlled and focus on the clinical impact that these alterations may have on fertility capacity. Furthermore, they should try as well to better elucidate the specific mechanisms through which exercise can exert its effects. Most authors are in agreement that exercise is beneficial for you but exercising in excess may cause problems which can also include problems with sexual potency.

\section{KEY POINTS}

- It is well known that exercise represents a form of physical stress that challenges homeostasis.

- Stress is accompanied by both an increase in the activity of the HPA axis and a decrease in the reproductive functions in order to preserve the organism's state of alert at the expense of gonadal activity. 
- $\quad$ The precise mechanism responsible for the changes in reproductive function remains unknown. However, observed changes include a reduction in total and free testosterone, alterations in LH release and alterations in pituitary responses to GnRH and other pharmacological perturbations.

- $\quad$ Exercise can lead to development of OS, increased testicular temperature, testicular microtrauma, and ED.

- There are differences in the seminal profiles of individuals exercising in different modalities.

- $\quad$ There may be a volume and intensity threshold above which both hormonal and semen parameters decline.

- Regular less demanding physical exercise does not seem to alter male reproductive function.

\section{ACKNOWLEDGEMENTS}

None Declared.

\section{CONFLICT OF INTEREST}

None Declared.

\section{REFERENCES}

[1] Top 10 List - Quotes About Exercise. Available from: http://www.inspirational-quotes-and-quotations.com/quotes-aboutexercise.html

[2] Morris JN, Heady JA. Mortality in relation to the physical activity of work: a preliminary note on experience in middle age. $\mathrm{Br} \mathrm{J}$ Ind Med 1953 Oct; 10(4): 245-54.

[3] Morris JN, Heady JA, Raffle PA, Roberts CG, Parks JW. Coronary heart-disease and physical activity of work. Lancet Nov 1953; 265(6795): 1053-7.

[4] Shivakumar G, Brandon AR, Snell PG et al. Antenatal depression: a rationale for studying exercise. Depress Anxiety 2010 Dec 13. [Epub ahead of print].

[5] Milani RV, Lavie CJ, Mehra MR, Ventura HO. Impact of Exercise Training and Depression on Survival in Heart Failure Due to Coronary Heart Disease. Am J Cardiol 2011; 107(1): 64-8.

[6] Colberg SR, Sigal RJ, Fernhall B et al. Exercise and Type 2 Diabetes: The American College of Sports Medicine and the American Diabetes Association: joint position statement. Diabetes care 2010; 33(12): 147-67.

[7] Ara I, Sanchez-Villegas A, Vicente-Rodriguez G et al. Physical Fitness and Obesity Are Associated in a Dose-Dependent Manner in Children. Ann Nutr Metab 2010; 57(3-4): 251-9.

[8] Reid KJ, Baron KG, Lu B, Naylor E, Wolfe L, Zee PC. Aerobic exercise improves self-reported sleep and quality of life in older adults with insomnia. Sleep Med 2010; 11(9): 934-40.

[9] Shaw K, Gennat H, O'Rourke P, Del Mar C. Exercise for overweight or obesity. Cochrane Database Syst Rev 2006; 18(4): CD003817.

[10] Vaamonde D, Da Silva-Grigoletto ME, Garcia-Manso JM. Sperm and hormonal differences between physically active and sedentary subjects: European Congress of Sport Sciences. Proceedings of the 14th Annual Congress of the European College of Sport Sciences; Olso, Norway; June 2009; Eds: Loland S, Bø K, Fasting K, Hallèn J, Ommundsen Y, Roberts G, Tsolakidis E; Gamlebyen Grafiske AS, Oslo, Greenland; 2009.

[11] Vaamonde D, Da Silva-Grigoletto ME, Garcia-Manso JM, Vaamonde-Lemos R. Improved values of gonadotropins in physically active subjects: European Congress of Sport Sciences. Proceedings of the 15th Annual Congress of the European Congress of Sport Sciences; June 2010; Middle East Technical University, Antalya, Turkey; 2010.
[12] Vaamonde D, Da Silva-Grigoletto ME, Garcia-Manso JM, Vaamonde-Lemos R, Swanson RJ, Oehninger SC. Response of semen parameters to three training modalities. Fertil Steril 2009; 92(6): 1941-6.

[13] Vaamonde D, Da Silva-Grigoletto ME, García-Manso JM, CunhaFilho JS, Vaamonde-Lemos R. Sperm morphology normalcy is inversely correlated to cycling kilometers in elite triathletes. Revista Andaluza de Medicina del Deporte 2009; 02: 43-6.

[14] Gillum TL, Dumke CL, Ruby BC. Muscle glycogenolysis and resynthesis in response to a half ironman triathlon: a case study. Int J Sports Physiol Perform 2006; 1(4): 408-13.

[15] La Gerche A, Connelly KA, Mooney DJ, MacIsaac AI, Prior DL. Biochemical and functional abnormalities of left and right ventricular function after ultra-endurance exercise. Heart. 2008; 94(7): 860-6.

[16] Scharhag J, George K, Shave R, Urhausen A, Kindermann W. Exercise-associated increases in cardiac biomarkers. Med Sci Sports Exerc 2008; 40(8):1408-15.

[17] Bessa A, Nissenbaum M, Monteiro A et al. High-intensity ultraendurance promotes early release of muscle injury markers. $\mathrm{Br}$ J Sports Med 2008; 42(11): 589-93.

[18] Bougault V, Turmel J, St-Laurent J, Bertrand M, Boulet LP. Asthma, airway inflammation, and epithelial damage in swimmers and cold-air athletes. Eur Respir J 2009; 33(4):740-6.

[19] Mastorakos G, Pavlatou M, Diamanti-Kandarakis E, Chrousos GP. Exercise and the stress system. Hormones 2005; 4(2): 73-89.

[20] Olive DL. Exercise and fertility: an update. Current opinion in obstetrics \& gynecology 2010; 22(4): 259-63.

[21] Schwartz B, Cumming DC, Riordan E, Selye M, Yen SS, Rebar RW. Exercise-associated amenorrhea: a distinct entity? American journal of obstetrics and gynecology 1981; 141(6): 662-70.

[22] Howe WB. Exercise and amenorrhea. American family physician. $1981 ; 24(2): 41$.

[23] Gudmundsdottir SL, Flanders WD, Augestad LB. Physical activity and fertility in women: the North-Trondelag Health Study. Hum Reprod (Oxford, England) 2009; 24(12): 3196-204.

[24] De Souza MJ. Menstrual disturbances in athletes: a focus on luteal phase defects. Med Sci Sports Exerc 2003; 35(9): 1553-63.

[25] Valentino R, Savastano S, Tommaselli AP, D’Amore G, Dorato M, Lombardi $\mathrm{G}$. The influence of intense ballet training on trabecular bone mass, hormone status, and gonadotropin structure in young women. Clin Endocrinol Metab 2001; 86: 4674-8.

[26] Klentrou P, Plyley M. Onset of puberty, menstrual frequency, and body fat in elite rhythmic gymnasts compared with normal controls. Br J Sports Med 2003; 37: 490-4.

[27] De Souza MJ, Leidy HJ, O’Donnell E, Lasley B, Williams NI. Fasting ghrelin levels in physically active women: relationship with menstrual distur-bances and metabolic hormones. J Clin Endocrinol Metab 2004; 89: 3536-42.

[28] Prather H, Hunt D. Issues unique to the female runner. Phys Med Rehabil Clin N Am 2005; 16: 691-709.

[29] Greenhall E, Vessey M. The prevalence of subfertility: a review of the current confusion and a report of two new studies. Fertility and sterility 1990; 54(6): 978-83.

[30] Joffe M. Time trends in biological fertility in Britain. Lancet 2000; 355(9219): 1961-5.

[31] Arce JC, De Souza MJ. Exercise and male factor infertility. Sports Med 1993; 15(3): 146-69.

[32] Hackney AC. Endurance training and testosterone levels. Sports Med 1989; 8(2): 117-27.

[33] Rubin RT, Poland RE, Sobel I, Tower BB, Odell WD. Effects of prolactin and prolactin plus luteinizing hormone on plasma testosterone levels in normal adult men. J Clin Endocrinol Metab 1978; 47(2): 447-52.

[34] Ayers JW, Komesu Y, Romani T, Ansbacher R. Anthropomorphic, hormonal, and psychologic correlates of semen quality in endurance-trained male athletes. Fertil steril 1985; 43(6): 917-21.

[35] Bagatell CJ, Bremner WJ. Sperm counts and reproductive hormones in male marathoners and lean controls. Fertil steril1990; 53(4): 688-92.

[36] Lucia A, Chicharro JL, Perez M, Serratosa L, Bandres F, Legido JC. Reproductive function in male endurance athletes: sperm analysis and hormonal profile. J Appl Physiol 1996; 81(6): 262736. 
[37] Arce JC, De Souza MJ, Pescatello LS, Luciano AA. Subclinical alterations in hormone and semen profile in athletes. Fertil Steril 1993; 59(2): 398-404

[38] Safarinejad MR, Azma K, Kolahi AA. The effects of intensive, long-term treadmill running on reproductive hormones, hypothalamus-pituitary-testis axis, and semen quality: a randomized controlled study. J Endocrinol 2009; 200(3): 259-71.

[39] Jensen CE, Wiswedel K, McLoughlin J, van der Spuy Z. Prospective study of hormonal and semen profiles in marathon runners. Fertil Steril 1995; 64(6): 1189-96.

[40] Gebreegziabher Y, Marcos E, McKinon W, Rogers G. Sperm characteristics of endurance trained cyclists. Int J Sports Med 2004; 25(4): 247-51.

[41] Hall HL, Flynn MG, Carroll KK, Brolinson PG, Shapiro S, Bushman BA. Effects of intensified training and detraining on testicular function. Clin J Sport Med 1999; 9(4): 203-8.

[42] De Souza MJ, Arce JC, Pescatello LS, Scherzer HS, Luciano AA. Gonadal hormones and semen quality in male runners. A volume threshold effect of endurance training. Int J Sports Med 1994; 15(7): 383-91.

[43] De Souza MJ, Miller BE. The effect of endurance training on reproductive function in male runners. A 'volume threshold' hypothesis. Sports medicine (Auckland, NZ) 1997; 23(6):357-74

[44] WHO. WHO Laboratory manual for the examination of human semen and sperm-cervical mucus interaction 4ed. Cambridge: Cambridge University Press 1999

[45] Vaamonde D, Da Silva ME, Poblador MS, Lancho JL. Reproductive profile of physically active men after exhaustive endurance exercise. Int J Sports Med 2006; 27(9): 680-9.

[46] Di Luigi L, Gentile V, Pigozzi F, Parisi A, Giannetti D, Romanelli F. Physical activity as a possible aggravating factor for athletes with varicocele: impact on the semen profile. Hum Reprod (Oxford, England) 2001; 16(6): 1180-4

[47] Burge MR, Lanzi RA, Skarda ST, Eaton RP. Idiopathic hypogonadotropic hypogonadism in a male runner is reversed by clomiphene citrate. Fertil Steril 1997; 67(4): 783-5.

[48] Leibovitch I, Mor Y. The vicious cycling: bicycling related urogenital disorders. Eur Urol 2005; 47(3):277-86; discussion 86-7. Southorn T. Great balls of fire and the vicious cycle: a study of the effects of cycling on male fertility. The journal of family planning and reproductive health care / Faculty of Family Planning \& Reproductive Health Care, Royal College of Obstetricians \& Gynaecologists 2002; 28(4): 211-3.

[50] Marceau L, Kleinman K, Goldstein I, McKinlay J. Does bicycling contribute to the risk of erectile dysfunction? Results from the Massachusetts Male Aging Study (MMAS). Int J Impot Res 2001; 13(5): 298-302.

[51] Sommer F, Schwarzer U, Klotz T, Caspers HP, Haupt G, Engelmann U. Erectile dysfunction in cyclists. Is there any difference in penile blood flow during cycling in an upright versus a reclining position? Eur Urol 2001; 39(6): 720-3.

[52] Dettori JR, Koepsell TD, Cummings P, Corman JM. Erectile dysfunction after a long-distance cycling event: associations with bicycle characteristics. J Urol 2004; 172(2): 637-41.

[53] Brant WO, Myers JB, Carrell DT, Smith JF. Male athletic activities and their effects on semen and hormonal parameters. Phys Sports Med 2010; 38(3): 114-20.

[54] Blank JL, Desjardins C. Spermatogenesis is modified by food intake in mice. Biol Repro 1984; 30(2): 410-5.

[55] Saris WH, van Erp-Baart MA, Brouns F, Westerterp KR, ten Hoor F. Study on food intake and energy expenditure during extreme sustained exercise: the Tour de France. Int J Sports Med 1989; 10 (Suppl 1): 26-31.

[56] Makker K, Agarwal A, Sharma R. Oxidative stress \& male infertility. Indian J Med Res 2009; 129(4): 357-67.

[57] Lewis SE, Sterling ES, Young IS, Thompson W. Comparison of individual antioxidants of sperm and seminal plasma in fertile and infertile men. Fertil Steril 1997; 67(1): 142-7.

[58] Dillard CJ, Litov RE, Savin WM, Dumelin EE, Tappel AL. Effects of exercise, vitamin E, and ozone on pulmonary function and lipid peroxidation. J Appl Physiol 1978; 45(6): 927-32

[59] Vollaard NB, Shearman JP, Cooper CE. Exercise-induced oxidative stress:myths, realities and physiological relevance. Sports med (Auckland, NZ) 2005; 35(12):1045-62.

[60] Kostaropoulos IA, Nikolaidis MG, Jamurtas AZ, et al. Comparison of the blood redox status between long-distance and short-distance runners. Physiological research / Academia Scientiarum Bohemoslovaca 2006; 55(6): 611-6.

[61] Knez WL, Jenkins DG, Coombes JS. Oxidative stress in half and full Ironman triathletes. Med Sci Sports Exerc 2007; 39(2): 283-8.

[62] Serrano E, Venegas C, Escames G, et al. Antioxidant defence and inflammatory response in professional road cyclists during a 4-day competition. J Sports Sci 2010; 28(10): 1047-56.

[63] Kothari S, Thompson A, Agarwal A, du Plessis SS. Free radicals: their beneficial and detrimental effects on sperm function. Indian J Exp Biol 2010; 48(5): 425-35.

[64] Cooper CE, Vollaard NB, Choueiri T, Wilson MT. Exercise, free radicals and oxidative stress. Biochem Soc Trans 2002; 30(2): 2805.

[65] Niess AM, Simon P. Response and adaptation of skeletal muscle to exercise-the role of reactive oxygen species. Front Biosci 2007; 12 : 4826-38.

[66] Goto C, Higashi Y, Kimura M, et al. Effect of different intensities of exercise on endothelium-dependent vasodilation in humans: role of endothelium-dependent nitric oxide and oxidative stress. Circulation 2003; 108(5): 530-5.

[67] Goto C, Nishioka K, Umemura T, et al. Acute moderate-intensity exercise induces vasodilation through an increase in nitric oxide bioavailiability in humans. Am J Hypertens 2007 Aug; 20(8): 82530

[68] Bloomer RJ, Davis PG, Consitt LA, Wideman L. Plasma protein carbonyl response to increasing exercise duration in aerobically trained men and women. Int J Sports Med 2007; 28(1): 21-5.

[69] Manna I, Jana K, Samanta PK. Intensive swimming exerciseinduced oxidative stress and reproductive dysfunction in male wistar rats: protective role of alpha-tocopherol succinate. Can J Appl Physiol 2004; 29(2): 172-85.

[70] Manna I, Jana K, Samanta PK. Effect of different intensities of swimming exercise on testicular oxidative stress and reproductive dysfunction in mature male albino Wistar rats. Indian J Exp Biol 2004; 42(8): 816-22.

[71] Fisher-Wellman K, Bloomer RJ. Acute exercise and oxidative stress: a 30 year history. Dyn Med 2009; 8: 1

[72] Kyparos A, Vrabas IS, Nikolaidis MG, Riganas CS, Kouretas D. Increased oxidative stress blood markers in well-trained rowers following two thousand-meter rowing ergometer race. J Strength Cond Res 2009; 23(5): 1418-26.

[73] Knez WL, Coombes JS, Jenkins DG. Ultra-endurance exercise and oxidative damage : implications for cardiovascular health. Sports Med (Auckland, NZ. 2006; 36(5): 429-41.

[74] Gomez-Cabrera MC, Domenech E, Vina J. Moderate exercise is an antioxidant: upregulation of antioxidant genes by training. Free Radic Biol Med 2008 Jan 15; 44(2): 126-31.

[75] Purvis D, Gonsalves S, Deuster PA. Physiological an psychological fatigue in extreme conditions: overtraining and elite athletes. Pm R 2010; 2(5): 442-50.

[76] Eskiocak S, Gozen AS, Kilic AS, Molla S. Association between mental stress \& some antioxidant enzymes of seminal plasma. Indian J Med Res 2005; 122(6): 491-6.

[77] Clarke RN, Klock SC, Geoghegan A, Travassos DE. Relationship between psychological stress and semen quality among in-vitro fertilization patients. Hum reprod (Oxford, England) 1999; 14(3): 753-8.

[78] Morelli G, De Gennaro L, Ferrara M, et al. Psychosocial factors and male seminal parameters. Biol Psychol 2000; 53(1): 1-11.

[79] Luger A, Deuster PA, Kyle SB, et al. Acute hypothalamicpituitary-adrenal responses to the stress of treadmill exercise. Physiologic adaptations to physical training. New England J Med 1987; 316(21): 1309-15.

[80] Viru M, Hackney AC, Karelson K, Janson T, Kuus M, Viru A. Competition effects on physiological responses to exercise performance, cardiorespiratory and hormonal factors. Acta Physiol Hung 2010; 97(1): 22-30.

[81] Fernández-Garcia B, Lucía A, Hoyos J, et al. The response of sexual and stress hormones of male pro-cyclists during continuous intense competition. Int J Sports Med 2002; 23(8): 555-60.

[82] Urhausen A, Kindermann W. Behaviour of testosterone, sex hormone binding globulin (SHBG), and cortisol before and after a triathlon competition. Int J Sports Med 1987; 8(5): 305-8.

[83] Papanicolaou DA, Petrides JS, Tsigos C, et al. Exercise stimulates interleukin-6 secretion: inhibition by glucocorticoids and correlation with catecholamines. Am J Physiol 1996; 271: 601-5. 
[84] Neubauer O, König D, Wagner KH. Recovery after an Ironman triathlon: sustained inflammatory responses and muscular stress. Eur J Appl Physiol 2008; 104(3): 417-26.

[85] Luger A, Watschinger B, Deuster P, Svoboda T, Clodi M, Chrousos GP. Plasma growth hormone and prolactin responses to graded levels of acute exercise and to a lactate infusion. Neuroendocrinology 1992; 56(1): 112-7.

[86] Ulisse S, Fabbri A, Dufau ML. Corticotropin-releasing factor receptors and actions in rat Leydig cells. J Biol Chem 1989; 264(4): 2156-63.

[87] Coldman AJ, Elwood JM, Gallagher RP. Sports activities and risk of testicular cancer. Br J Cancer 1982; 46(5): 749-56.

[88] Bennell KL, Brukner PD, Malcolm SA. Effect of altered reproductive function and lowered testosterone levels on bone density in male endurance athletes. Br J Cancer 1996; 30(3): 205-8.

[89] MacConnie SE, Barkan A, Lampman RM, Schork MA, Beitins IZ. Decreased hypothalamic gonadotropin-releasing hormone secretion in male marathon runners. New Eng J Med 1986; 315(7): 411-7.

[90] Lehmann MJ, Lormes W, Opitz-Gress A, et al. Training and overtraining: an overview and experimental results in endurance sports. J Sports Med Phys Fitness 1997; 37(1): 7-17.

[91] Mäestu J, Jürimäe J, Jürimäe T. Hormonal response to maximal rowing before and after heavy increase in training volume in highly trained male rowers. J Sports Med Phys Fitness 2005; 45(1):121-6.

[92] Naessens G, De Slypere JP, Dijs H, Driessens M. Hypogonadism as a cause of recurrent muscle injury in a high level soccer player. A case report. Int J Sports Med 1995; 16(6): 413-7.

[93] Meeker JD, Godfrey-Bailey L, Hauser R. Relationships between serum hormone levels and semen quality among men from an infertility clinic. J Androl 2007; 28(3): 397-406.

[94] Zorgniotti AW. Intrinsic testicular temperature elevation and subfertile semen. Adv Exp Med Biol 1991; 286: 199-202.

[95] Evenson DP, Jost LK, Corzett M, Balhorn R. Characteristics of human sperm chromatin structure following an episode of influenza and high fever: a case study. J Androl 2000; 21(5): 739-46.
[96] Mieusset R, Bujan L. Testicular heating and its possible contributions to male infertility: a review. Int J Androl 1995; 18(4): 169-84.

[97] Setchell BP. The Parkes Lecture. Heat and the testis. J Reprod Fertil 1998; 114(2): 179-94.

[98] Sharpe RM. Lifestyle and environmental contribution to male infertility. Br Med Bull 2000; 56(3): 630-42.

[99] Jung A, Strauss P, Lindner HJ, Schuppe HC. Influence of moderate cycling on scrotal temperature. Int J Androl 2008; 31(4): 403-7.

[100] Jung A, Leonhardt F, Schill WB, Schuppe HC. Influence of the type of undertrousers and physical activity on scrotal temperature. Humreprod (Oxford, England) 200; 20(4): 1022-7.

[101] Cherington M. Hazards of bicycling: from handlebars to lightning. Semin Neurol 2000; 20(2): 247-53.

[102] Silbert PL, Dunne JW, Edis RH, Stewart-Wynne EG. Bicycling induced pudendal nerve pressure neuropathy. Clin Exp Neurol 1991; 28: 191-6.

[103] Claudino MA, Delbin MA, Franco-Penteado CF, et al. Exercise training ameliorates the impairment of endothelial and nitrergic corpus cavernosum responses in diabetic rats. Life Sci 2011; 88(56): 272-7.

[104] Andersson KE, Stief CG. Neurotransmission and the contraction and relaxation of penile erectile tissues. World J Urol 1997; 15(1): $14-20$.

[105] Sommer F, Konig D, Graft C, et al. Impotence and genital numbness in cyclists. Int J Sport Med 2001; 22(6): 410-3.

[106] Mitterberger M, Pinggera GM, Neuwirt H, et al. Do mountain bikers have a higher risk of scrotal disorders than on-road cyclists. Clin J Sport Med 2008; 18(1): 49-54.

[107] Nargund VH. Health issues of cycling in men. BJU Int 2008; 102(7): 771-2.

[108] Frauscher F, Klauser A, Stenzl A, Helweg G, Amort B, Zur Nedden D. US findings in the scrotum of extreme mountain bikers. Radiology 2001; 219(2): 427-31.

[109] Hillman M. Cycling offers important health benefits and should be encouraged. Br Med J (Clin Res Ed). 1997; 315(7106): 490.

Received: January 02, 2010

(C) du Plessis et al.; Licensee Bentham Open.

This is an open access article licensed under the terms of the Creative Commons Attribution Non-Commercial License (http://creativecommons.org/licenses/by$\mathrm{nc} / 3.0 /$ ), which permits unrestricted, non-commercial use, distribution and reproduction in any medium, provided the work is properly cited. 